\title{
Detection and characterization of diverse alpha- and betacoronaviruses from bats in China
}

\author{
Lin $\mathrm{Xu}^{1 \#}$, Fuqiang Zhang ${ }^{2 \#}$, Weihong Yang ${ }^{3 \#}$, Tinglei Jiang ${ }^{4 \#}$, Guanjun $\mathrm{Lu}^{4}, \mathrm{Biao} \mathrm{He}^{1}, \mathrm{Xingyu} \mathrm{Li}^{1}$, \\ Tingsong $\mathrm{Hu}^{2}$, Gang Chen ${ }^{2}$, Yun Feng ${ }^{3}$, Yuzhen Zhang ${ }^{3}$, Quanshui Fan ${ }^{2}$, Jiang Feng ${ }^{4}$, Hailin Zhang ${ }^{3}$, \\ Changchun $\mathrm{Tu}^{1,5 \bowtie}$
}

1. Military Veterinary Institute, Academy of Military Medical Sciences, Changchun 130122, China

2. Center for Disease Control and Prevention of Chengdu Military Region, Kunming 650118, China

3. Yunnan Institute of Endemic Diseases Control and Prevention, Dali 671000, China

4. School of Urban and Environmental Sciences, Northeast Normal University, Changchun 130024, China

5. Jiangsu Co-innovation Center for Prevention and Control of Important Animal Infectious Diseases and

Zoonoses, Yangzhou 225009, China

Bats have been implicated as important reservoir hosts of alpha- and betacoronaviruses. In this study, diverse coronaviruses (CoVs) were detected in 50 of 951 (positive rate 5.3\%) intestinal specimens of eight bat species collected in four provinces and the Tibet Autonomous Region of China by pan-coronavirus RT-PCR screening. Based on 400-nt RNA-dependent RNA polymerase $(R d R P)$ sequence analysis, eight belonged to genus Alphacoronavirus and $\mathbf{4 2}$ to Betacoronavirus. Among the 50 positive specimens, thirteen gave rise to CoV full-length $R d R P$ gene amplification for further sequence comparison, of which three divergent sequences (two from a unreported province) were subjected to full genome sequencing. Two complete genomes of betacoronaviruses (JTMC15 and JPDB144) and one nearly-complete genome of alphacoronavirus (JTAC2) were sequenced and their genomic organization predicted. The present study has identified additional numbers of genetically diverse bat-borne coronaviruses with a wide distribution in China. Two new species of bat CoV, identified through sequence comparison and phylogenetic analysis, are proposed.

\section{KEYWORDS bats; Alphacoronavirus; Betacoronavirus; diversity}

\section{INTRODUCTION}

Coronaviruses (CoVs, family Coronaviridae, subfamily Coronavirinae) are important human and animal pathogens which, according to the latest release of Virus Taxonomy by the International Committee on Taxonomy of Viruses (ICTV, http://www.ictvonline.org/virusTaxonomy.asp?msl_id=26), currently comprise four distinct genera: Alphacoronavirus ( $\alpha \mathrm{CoV})$, Betacoronavirus

Received: 15 January 2016, Accepted: 21 January 2016

Published online: 2 February 2016

\# These authors contributed equally to this work.

$\triangle$ Correspondence:

Phone: +86-431-81032202, Fax: +86-431-81032202

Email: changchun_tu@hotmail.com

ORCID: 0000-0002-8134-7502 $(\beta \mathrm{CoV})$, Gammacoronavirus $(\gamma \mathrm{CoV})$ and Deltacronavir$u s(\delta C o V)$. This large group of viruses has a wide spectrum of hosts, including humans, rodents, carnivores, chiropters and avians, and cause respiratory, enteric, hepatic and neurological diseases (Lai et al, 2007). They include even public threats such as the severe acute respiratory syndrome (SARS) and the current Middle East respiratory syndrome (MERS) (Moratelli et al, 2015). Bats are host animals of diverse $\alpha \mathrm{CoVs}$ and $\beta \mathrm{CoVs}$ that may serve as the ancestral origins of mammalian CoVs (Falcon et al, 2011; Woo et al, 2012). In last decade, increasing numbers of bat CoVs with wide molecular diversities have been reported worldwide, particularly in China (Li et al, 2005; Tang et al, 2006; Woo et al, 2007; Chu et al, 2008; Yuan et al, 2010; He et al, 2014), some of 
which likely have the potential ability to cause human diseases (Ge et al, 2013; He et al, 2014; Menachery et al, 2015). These findings indicate that further diverse CoVs circulate in bat populations. China has a nationwide distribution of about 120 bat species, with many roosting regions remaining uninvestigated for harbored mammal viruses. Here, we report a continuing investigation on bat-borne CoVs in some unexplored regions in China, the results of which have revealed more novel CoVs that circulate and evolve in bat populations with great molecular diversity and wide geographic distribution.

\section{MATERIALS AND METHODS}

\section{Bat collection and species conformation}

A total of 951 bats covering 5 families and 21 species were captured between 2005 and 2013, in Jilin, Liaoning, Yunnan, Guangdong provinces and the Tibet Autonomous Region, China. Bat species were morphologically identified by a trained field biologist and further confirmed by PCR of their mitochondrial cytochrome $b$ gene sequence (Wang et al, 2003). Respiratory and intestinal tissue specimens were collected separately from each bat and stored at $-80{ }^{\circ} \mathrm{C}$ immediately until further processing.

\section{RNA extraction and detection by RT-PCR}

Viral RNA of each specimen was extracted by using the RNeasy Mini Kit (Qiagen, Hilden, Germany), and was immediately reverse-transcribed with the Superscript III Kit (Invitrogen, San Diego, CA) using random primers. Pan-CoV nested PCR primers were used to amplify a 440 -nt sequence in the RNA-dependent RNA polymerase (RdRP) gene by our published methods (He et al. 2014) (see Supplementary Table S1 for primer information). Expected PCR amplicons were directly sequenced by the Sanger method in an ABI 3730 sequencer (Comate Bio, Changchun, China).

\section{$R d R P$ gene amplification and whole genome sequencing}

The complete $R d R P$ genes of positive samples were amplified using LA Taq (TaKaRa, Dalian, China). Primers were designed based on $R d R P$ gene sequences of representative $\alpha \mathrm{CoV}$ and $\beta C o V$ strains available in GenBank. Reactions were carried out with a touch-down PCR program: $94{ }^{\circ} \mathrm{C}$ for $3 \mathrm{~min}$, then 10 temperature decrement cycles $\left(94{ }^{\circ} \mathrm{C}\right.$ for $30 \mathrm{~s}, 58^{\circ} \mathrm{C}$ minus $1{ }^{\circ} \mathrm{C}$ per cycle for $30 \mathrm{~s}, 72{ }^{\circ} \mathrm{C}$ for $2 \mathrm{~min}$ ), followed by 35 normal cycles $\left(94{ }^{\circ} \mathrm{C}\right.$ for $30 \mathrm{~s}, 52^{\circ} \mathrm{C}$ for $30 \mathrm{~s}, 72{ }^{\circ} \mathrm{C}$ for $\left.3 \mathrm{~min}\right)$, and a last extension of $72{ }^{\circ} \mathrm{C}$ for $10 \mathrm{~min}$.

To obtain the full genomes of the interesting specimens, overlapping amplicons were obtained by the above PCR program following by assembly into contigs. In ad- dition, deep sequencing and genome walking were also undertaken to recover more genomic sequences. The $5^{\prime}$ and $3^{\prime}$ termini were sequenced using a 5' Full RACE Kit with TAP and a 3' Full RACE Core Set with PrimeScript RTase (TaKaRa, Dalian, China). Primer sequences for full-length genome amplification are shown in Supplementary Table S1.

\section{Genomic and phylogenetic analyses}

Genomic structures of the $\mathrm{CoV}$ complete sequences were predicted by the SeqBuilder program of the DNAStar software package and compared with other representatives from GenBank. Nonstructural proteins (nsps) in ORF1a and ORF1b (replicase) of the CoVs were predicted using Z-Curve version 2.0, a CoV-specific genefinding system (Gao et al, 2003).

All 400-bp amplicons (the primer truncation of 440-nt sequences) were aligned with their closest phylogenetic neighbors in GenBank using Clustal W version 2.0. The phylogenetic tree was then constructed by the maximum likelihood method of MEGA 6.06 with 1,000 bootstrap replications. To better understand their evolutionary relationships, the complete $R d R P$ genes were further amplified and used for the analysis.

\section{Nucleotide sequence accession numbers}

The partial $R d R P$ sequences obtained from all positive samples and the complete genome or full length $R d R P$ sequences of some specimens were submitted to the GenBank under accession numbers KU182954 to KU183005.

\section{RESULTS}

\section{Detection of CoVs}

Of 951 bats tested 50 intestinal specimens $(5.3 \%)$ were $\mathrm{CoV}$ positive, but surprisingly all respiratory specimens showed negative amplification. As shown in Table 1, among 181 bats from 6 species in 3 families in Guangdong province, $16.2 \%$ (6/37) Rousettus leschenaultia and 27.5\% (14/51) Cynopterus sphinx were CoV positive. Among 599 bats from 17 species in 5 families in Yunnan province, $14.0 \%(14 / 100)$ Rousettus leschenaulti, $2.4 \%$ (1/41) Megaerops kusnotei, 9.0\% (7/78) Rhinolophus sinicus and 5.3\% (5/95) Myotis daubentonii were $\mathrm{CoV}$ positive. As the first study of this kind in the Tibet Autonomous Region, fifteen Hipposideros cineraceus and five Rhinolophus hipposideros collected in south Tibet were tested and only $6.7 \%(1 / 15)$ Hipposideros cineraceus showed positive amplification. In northeast China, 2 of $97(2.1 \%)$ bats in Jilin province were positive: one from Murina leucogaster and another from Rhinolophus ferrumequinum. In contrast, all 16 Rhinolophus ferrumequinum and 38 Myotis ricketti in Liaoning 
Table 1. Bat sample collection and coronavirus detection.

\begin{tabular}{|c|c|c|c|c|c|c|c|c|c|c|c|}
\hline \multicolumn{2}{|l|}{ Bats } & \multicolumn{2}{|c|}{$\begin{array}{l}\text { Guangdong } \\
\text { (Year 2005) }\end{array}$} & \multicolumn{2}{|c|}{$\begin{array}{c}\text { Yunnan } \\
\text { (Years 2012, 2013) }\end{array}$} & \multicolumn{2}{|c|}{$\begin{array}{c}\text { Tibet } \\
\text { (Year 2013) }\end{array}$} & \multicolumn{2}{|c|}{$\begin{array}{l}\text { Liaoning } \\
\text { (Year 2013) }\end{array}$} & \multicolumn{2}{|c|}{$\begin{array}{c}\text { Jilin } \\
\text { (Year 2013) }\end{array}$} \\
\hline Family & Species & $\mathrm{Bat}^{\S}$ & $\mathrm{CoV}^{\&}$ & Bat & $\mathrm{CoV}$ & Bat & $\mathrm{CoV}$ & Bat & $\mathrm{CoV}$ & Bat & $\mathrm{CoV}$ \\
\hline \multirow[t]{3}{*}{ Pteropodidae } & $\begin{array}{l}\text { Rousettus } \\
\text { leschenaulti }\end{array}$ & $6 / 37(16.2)$ & $\beta 4$ & $14 / 100(14.0)$ & $\beta 4$ & & & & & & \\
\hline & $\begin{array}{l}\text { Cynopterus } \\
\text { sphinx }\end{array}$ & $14 / 51(27.5)$ & $\beta 4$ & & & & & & & & \\
\hline & $\begin{array}{l}\text { Megaerops } \\
\text { kusnotei }\end{array}$ & & & $1 / 41(2.4)$ & $\beta 4$ & & & & & & \\
\hline \multirow[t]{5}{*}{ Hipposideridae } & $\begin{array}{l}\text { Hipposideros } \\
\text { cineraceus }\end{array}$ & $0 / 9$ & & & & $1 / 15(6.7)$ & $\alpha$ & & & & \\
\hline & $\begin{array}{l}\text { Hipposideros } \\
\text { pomona }\end{array}$ & & & $0 / 84$ & & & & & & & \\
\hline & $\begin{array}{l}\text { Hipposideros } \\
\text { larvatus }\end{array}$ & $0 / 68$ & & $0 / 2$ & & & & & & & \\
\hline & $\begin{array}{l}\text { Hipposideros } \\
\text { armiger }\end{array}$ & $0 / 11$ & & $0 / 18$ & & & & & & & \\
\hline & $\begin{array}{l}\text { Aselliscus } \\
\text { stoliczkanus }\end{array}$ & & & $0 / 33$ & & & & & & & \\
\hline \multirow[t]{6}{*}{ Rhinolophidae } & $\begin{array}{l}\text { Rhinolophus } \\
\text { ferrumequinum }\end{array}$ & & & $0 / 42$ & & & & $0 / 16$ & & 1/30(3.3) & ) $\beta 2$ \\
\hline & $\begin{array}{l}\text { Rhinolophus } \\
\text { sinicus }\end{array}$ & & & $7 / 78(9.0)$ & $\alpha, \beta 2$ & & & & & & \\
\hline & $\begin{array}{l}\text { Rhinolophus } \\
\text { pusillus }\end{array}$ & $0 / 5$ & & $0 / 6$ & & & & & & & \\
\hline & $\begin{array}{l}\text { Rhinolophus } \\
\text { affinis }\end{array}$ & & & $0 / 3$ & & & & & & & \\
\hline & $\begin{array}{l}\text { Rhinolophus } \\
\text { hipposideros }\end{array}$ & & & $0 / 37$ & & $0 / 5$ & & & & & \\
\hline & $\begin{array}{l}\text { Rhinolophus } \\
\text { macrotis }\end{array}$ & & & & & & & & & & \\
\hline \multirow[t]{7}{*}{ Vespertilionidae } & $\begin{array}{l}\text { Myotis } \\
\text { daubentonii }\end{array}$ & & & $5 / 95(5.3)$ & $\beta 3$ & & & & & & \\
\hline & Myotis laniger & & & $0 / 8$ & & & & & & & \\
\hline & $\begin{array}{l}\text { Myotis } \\
\text { chinensis }\end{array}$ & & & $0 / 3$ & & & & & & & \\
\hline & $\begin{array}{l}\text { Myotis } \\
\text { capaccinii }\end{array}$ & & & $0 / 40$ & & & & & & & \\
\hline & Myotis ricketti & & & & & & & $0 / 38$ & & $0 / 27$ & \\
\hline & $\begin{array}{l}\text { Miniopterus } \\
\text { schreibersi }\end{array}$ & & & $0 / 8$ & & & & & & & \\
\hline & $\begin{array}{l}\text { Murina } \\
\text { leucogaster }\end{array}$ & & & & & & & & & $1 / 40(2.5)$ & ) $\alpha$ \\
\hline Megadermatidae & $\begin{array}{l}\text { Megaderma } \\
\text { Iyra }\end{array}$ & & & $0 / 1$ & & & & & & & \\
\hline
\end{tabular}

Note: ${ }^{\S}$ positive/total bats; numbers in brackets indicate the coronavirus positive percentage. ${ }^{\circledR} \mathrm{CoV}, \alpha$ : $\alpha \mathrm{CoV} ; \beta$ : unclassified $\beta \mathrm{CoV} ; \beta 2$ : $\beta \mathrm{CoV}$ lineage $2 ; \beta 3$ : $\beta \mathrm{CoV}$ lineage $3 ; \beta 4$ : $\beta \mathrm{CoV}$ lineage 4.

province showed negative amplification. These results revealed a higher $\mathrm{CoV}$ incidence in three fruit bat species of the family Pteropodidae than in the four insectivorous bat families, indicating that fruit bats are more likely to harbor CoVs.

\section{Phylogenetic analysis}

To describe the genetic relationships among the 50 sequences obtained in this study and previously known
CoVs, 400-nt $R d R P$ sequences were obtained from the primer truncation of 440-nt sequences and phylogenetically analyzed. Results showed that 8 sequences grouped into 3 clusters within the genus $\alpha \mathrm{CoV}$ (Figure 1A). YDB5C is the first reported bat-borne $\mathrm{CoV}$ (Hipposideros cineraceus) in Tibet and clustered closely with MLHJC4, a CoV from Rhinolophus sinicus in Yunnan, both sharing 94\% nt identity with previously reported strain HKU2/ GD/430/2006 from Guangdong (Lau et al, 2007). JTAC2 
identified in Murina leucogaster in Jilin province diverged considerably from known CoVs, showing the highest nt identity of only $83 \%$ to bat-borne coronavirus Neixiang-14 and Neixiang-52 detected also in Murina leucogaster, and followed by $78 \%$ nt identity with some pandemic porcine epidemic diarrhea virus (PEDV) strains that have emerged recently in China, USA and Japan (Vlasova et al, 2014; Sun et al, 2015; Suzuki et al, 2015). Five other $\alpha \mathrm{CoVs}$ (MLHJC1, MLHJC6, MLHJC8, MLHJC22, MLHJC34) identified from Rhinolophus sinicus in Yunnan formed a new group with MLHJC8 being slightly more divergent, showing highest nt identities (75\%-89\%) with the previously reported $\mathrm{BtCoV} / 860 / 2005$ (Tang et al, 2006). The remaining 42 bat $\mathrm{CoV}$ sequences were classified as $\beta \mathrm{CoV}$ and fell into 5 clusters (Figure 1B). Twenty identified in Guangdong fell into lineage $\beta 4$, which showed the geographical relationship and was further divided into two distinct clusters, one with 6 sequences sharing 99\% highest nt identity with HKU9-101 (Lau et al, 2010), while another including 14 sequences sharing the closest relationship with $\mathrm{BtCoV} /$ BRT55630/H.lek/CK/Tha/05/2012 detected in Hipposideros lekaguli in Thailand (Wacharapluesadee et al, 2015). The $21 \beta \mathrm{CoVs}$ identified in Yunnan province exhibited considerable genetic diversity and were distributed among lineages $\beta 2, \beta 3$ and $\beta 4$. Fifteen fell into $\beta 4$ and further divided into 2 lineages, fourteen sequences showing closest relationship to previously reported BtCoV/BRT55629/H.lek/CK/Tha/05/2012 (Wacharapluesadee et al, 2015), while another (ML92C) grouped with the

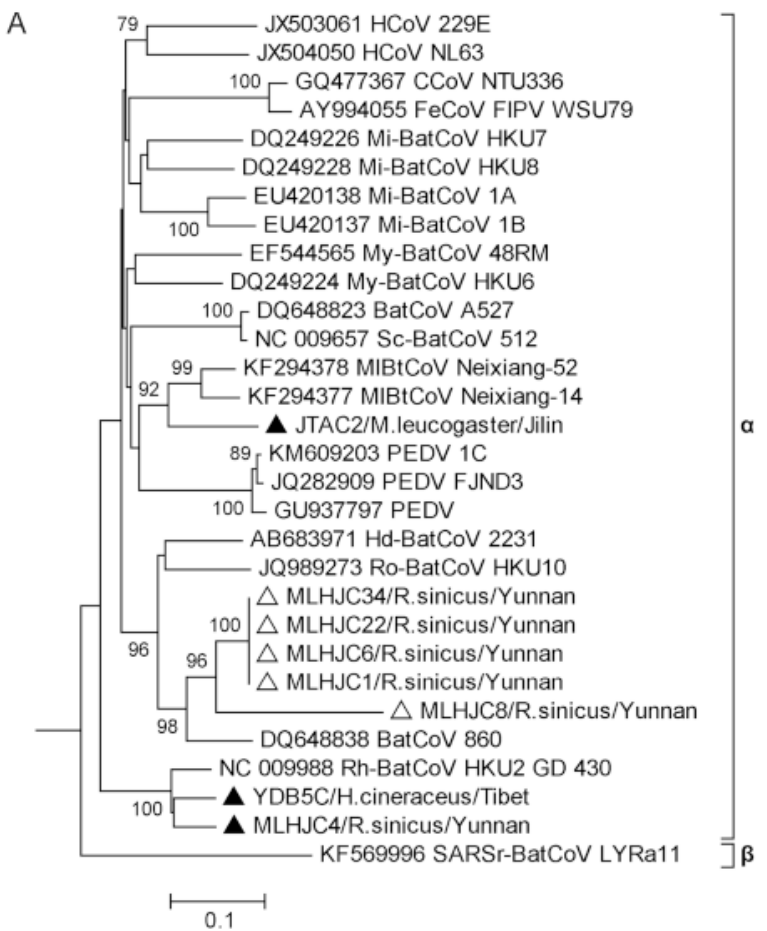

B

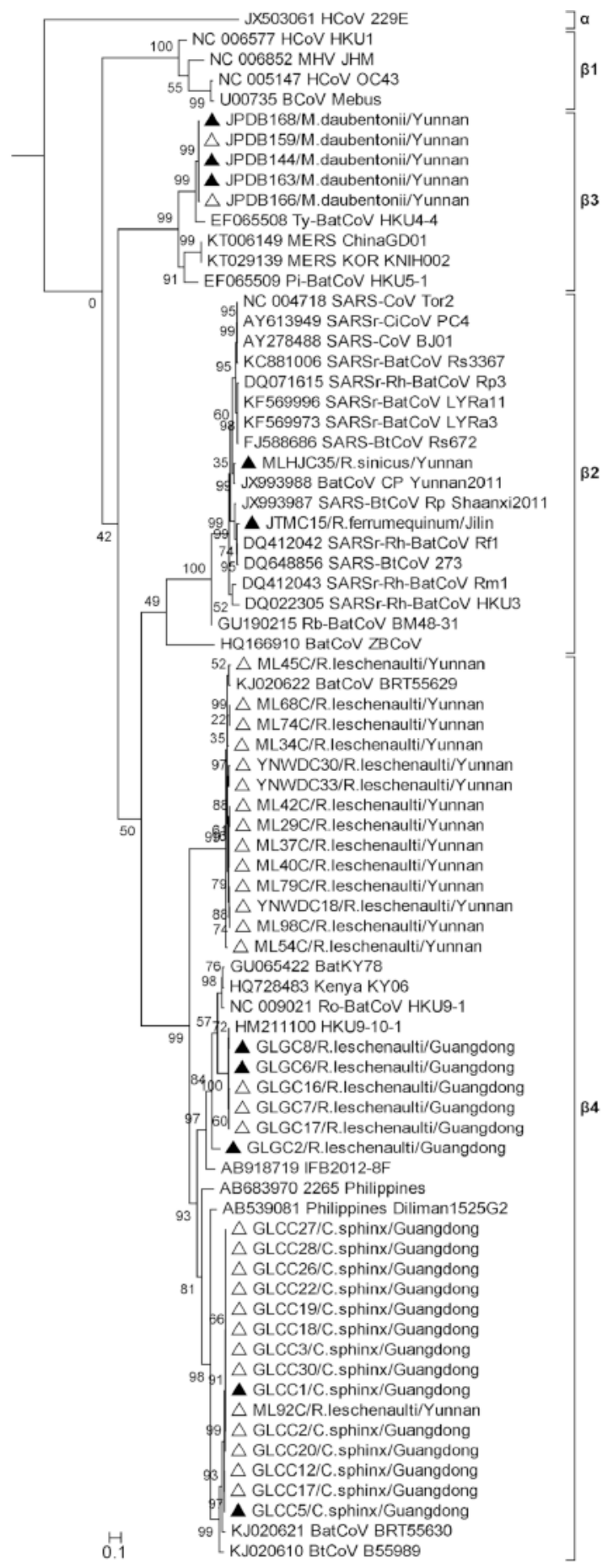

Figure 1. The 400-nt RdRP gene fragment based phylogenetic analysis of 50 bat CoV sequences obtained in this study ( 8 sequences of $\alpha \mathrm{CoV}$ in $(\mathrm{A})$ and 42 sequences of $\beta C \mathrm{C} V$ in $(B))$ in comparison with other representative strains retrieved from GenBank. Fifty sequences of this study are marked by triangles (13 sequences with complete RdRP gene sequencing are marked by solid triangles). The scale bar indicates the estimated number of substitutions per 10 nucleotides. 
above Guangdong sequences. Five sequences detected from Myotis daubentonii clustered within lineage $\beta 3$, sharing $>91 \% \mathrm{nt}$ identities with previously reported HKU4-4 from Tylonycteris pachypus (Woo et al, 2007). This group showed about $80 \%$ nt identity with MERSCoVs recently identified in China (Lu et al, 2015) and Korea (Kim et al, 2015). The remaining Yunnan bat $\mathrm{CoV}$ sequence, MLHJC35, detected in Rhinolophus sinicus, and the only Jilin province sequence, JTMC15, identified in Rhinolophus ferrumequinum were clustered into $\beta 2$ and showed highest nt identities to SARS-related batborne CoVs (SARSr-BatCoVs). MLHJC35 was 97\% identical with SARSr-BatCoV Cp/Yunnan2011 previously isolated in Yunnan province (Yang et al, 2011), while JTMC15 shared 99\% identity with SARSr-Bat$\mathrm{CoV}$ Rf1 found in Rhinolophus ferrumequinum, Hubei province (Li et al, 2005).

To obtain more precise analysis, representative specimens of the 8 phylogenetic clusters were subjected to full $R d R P$ gene amplification. Complete $R d R P$ sequences were obtained with 13 specimens belonging to 6 clusters comprised of $3 \alpha \mathrm{CoVs}$ and $10 \beta \mathrm{CoVs}$. Phylogenetic analysis based on the full $R d R P$ gene sequences was highly consistent with Figure 1 (Phylogenetic tree of the full $R d R P$ gene sequences is not shown).

\section{Full genomic sequences characterization}

Full genomic sequencing was successful in 2 of the above 13 specimens: JTMC15 from Rhinolophus ferrumequinum, Jilin province, and JPDB144 from Myotis daubentonii, Yunnan province, with a nearly complete genome sequence obtained of JTAC2 from Murina leucogaster. The full genomes of JTMC15 and JPDB144 (including complete terminal sequences of $5^{\prime}$ end and $3^{\prime}$ poly A) and near-complete genome of JTAC2 were $28,761 \mathrm{nt}, 30,321 \mathrm{nt}$ and 25,719 $\mathrm{nt}$ in size respectively, with $\mathrm{G}+\mathrm{C}$ contents of $38.1 \%, 41.0 \%$ and $43.4 \%$. It is proved that two proteinases, papain-like proteinase $\left(\mathrm{PL}^{\mathrm{Pro}}\right)$ encoded by $n s p 3$ gene and main proteinase $\left(\mathrm{M}^{\mathrm{Pro}}\right)$ encoded by $n s p 5$ gene in ORF1a of CoVs are able to cleave the complex of ORF1a and ORF1b (replicase) into 16 mature nonstructural proteins (nsps) (Neuman et al, 2008). Our analysis of the nsps in ORF 1 ab revealed that all the three bat $\mathrm{CoV}$ genomic sequences contain $16 \mathrm{nsps}$ (nsp1-nsp16) in ORF1ab, but the cleavage sites are different for nsp3 or nsp5 in different CoVs. The length of deduced amino acids of putative nsps, their first-last residue and position in replicase are shown in Supplementary Table S2.

Base on the nearly complete genomic sequence obtained, JTAC2 possesses the same genome structure as PEDVs with 7 genes in the order: 5'-ORF $1 a, 1 b$, spike $(S), 3 a$, envelope $(E)$, membrane $(M)$ and nudeocapsid $(N)-3$ ' (Figure 2A). JTAC2 showed the nearest relation- ship (87.9\% in ORF1a and $92.8 \%$ in ORF $1 b)$ with Lushi MI bat CoV isolates Neixiang-14 and Neixiang-52, but the latter two have very limited sequences available for further analysis. The recent PEDV-1C isolated from a piglet with diarrhea and vomiting (Sun et al, 2015) was therefore used for sequence comparison and genomic organization analysis, since it has been fully sequenced and shares high identity with JTAC2 (Figure 1A and Supplementary Table S3). The aa identity comparison shown in Supplementary Table S3 suggests that JTAC2 is a novel $\alpha \mathrm{CoV}$.

JTMC15 is a SARSr-BatCoV having the same genome organization as other SARSr-BatCoVs (e.g., Rf1), but sequence deletions were observed in ORFI $a$ and $N$, and between genes $7 b-8$. A 579-nt deletion in ORF1a of JTMC15 was also observed in SARSr-BatCoV Rs672 from a Rhinolophus sinicus bat (Yuan et al, 2010) and a human SARS-CoV ShanghaiQXC2 from the late phase of the 2003 epidemic (GenBank \#AY463060). This 579nt deletion results in a 193-aa deletion of $n s p 3$ in ORF1a, from residues 1059 to 1251 in the nucleic acid-binding (NAB) domain (Serrano et al, 2009). A second deletion in the $N$ gene of JTMC15 (1156-1158 nt, one residue $\mathrm{Q}^{368}$ ) was also found in 3 SARSr-BatCoV strains, $\mathrm{Rp} /$ Shaanxi2011 (Yang et al, 2013), Rm1 (Li et al, 2005) and 279/2005 (Tang et al, 2006). Interestingly, four discontinuous deletions were identified in JTMC15 between genes $7 b$ and 8 , which is unique in JTMC15, resulting in an ORF shift and elimination of gene 8 (Figure 2B). Similar to known CoVs, extensive $S$ gene variations were also observed in JTMC15, resulting in low aa identities with other SARSr-BatCoV strains (the highest being $86.1 \%$ to $\mathrm{Rf} 1$ ) as compared with other gene fragments in the genome. Receptor-binding motif (RBM) is an extended loop that lies on the surface of the receptor binding domain (RBD) of the spike protein, and is the most important domain for SARSr-BatCoV to recognize its host receptor, angiotensin-converting enzyme 2 (ACE2) (Ren et al, 2008; Baez-Santos et al, 2015). Further alignment of the deduced amino acid sequences of RBM (55 aa) showed a closer relationship of JTMC15 to SARSr-BatCoVs than to human or civet SARS-CoVs (Supplementary Figure S1). Taking the above altogether, as shown in Figure 2A and Table 2, there are 13 genes predicted in JTMC15: 5'-ORF1a, $1 b, S, 3 a, 3 b, E, M, 6$, $7 a, 7 b, N, 9 a, 9 b-3^{\prime}$. Apart from gene $7 b(83.0 \%)$ and $S$ $(86.1 \%)$ all ORFs of JTMC15 had high aa identities to Rf1, ranging from $94.4 \%$ ( $9 b$ gene) to $99.1 \%$ ( $M$ gene), indicating that JTMC15 is a new variant within the SARSr-BatCoV Rfl species.

For JPDB144, the genome organization is almost the same as HKU4-4, with 10 genes in the order: 5'-ORF1a, $1 b, S, 3 a, 3 b, 3 c, 3 d, E, M, N-3^{\prime}$ (Figure 2A). However, two differences were observed in the nsp2 of JPDB144: 
A
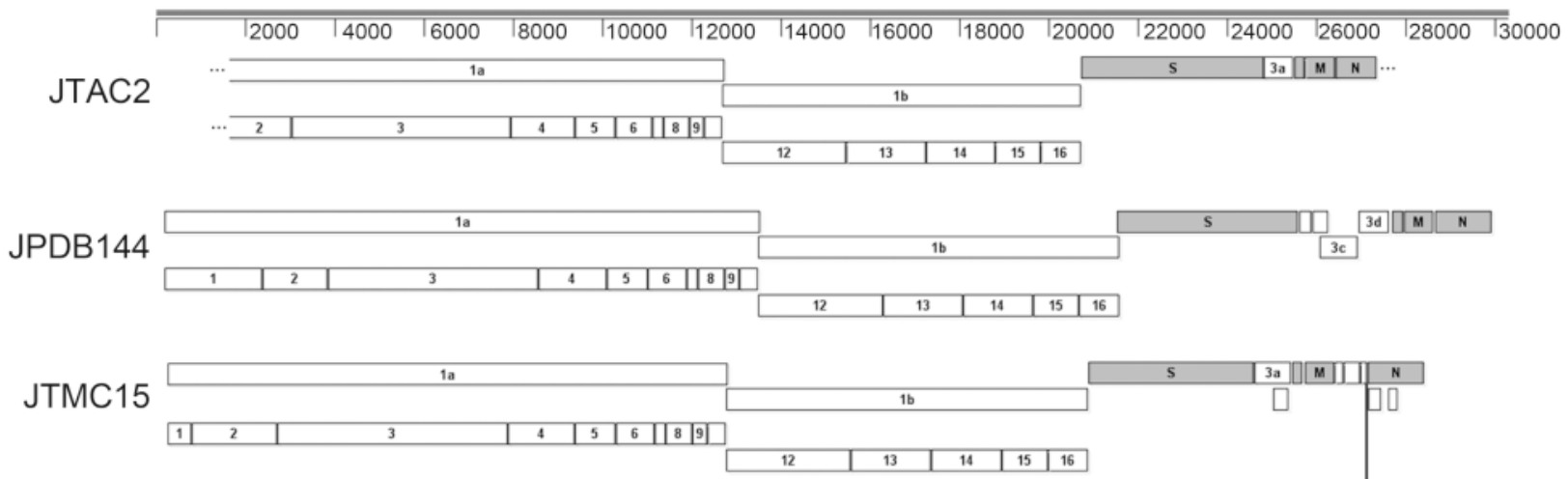

B

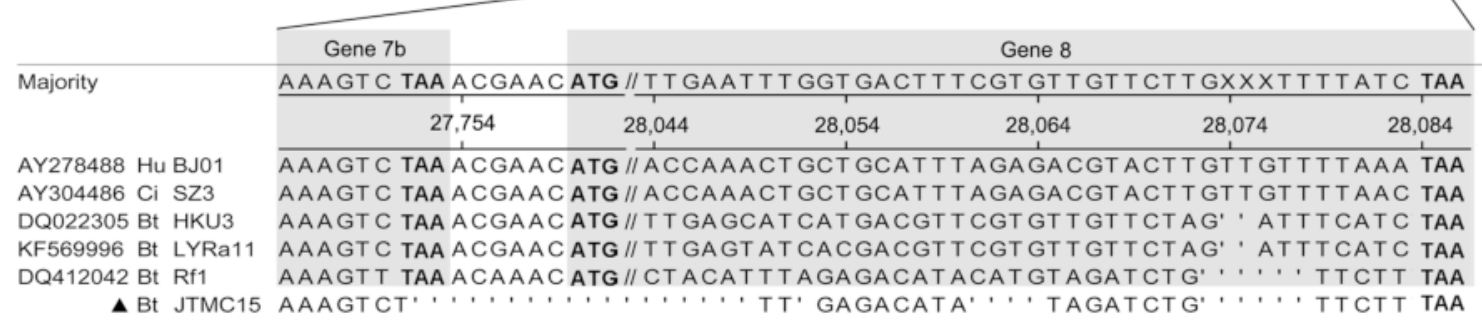

Figure 2. Predicted genome organizations of JTAC2, JTMC15 and JPDB144. (A) Nonstructural proteins are represented by open boxes, structural proteins by filled boxes. Apostrophes in JTAC2 identify unsequenced regions. (B) Sequence comparison showing the ORF shift of gene $7 b$ of JTMC15 caused by the discontinuous deletions (represented by dots), resulting in elimination of gene 8 as compared to other SARS- and SARSr-CoVs. Nucleotide position are determined referencing strain BJ01. Stop codons and start codons are in bold fonts. Hu: human SARS-CoV; Ci: civet SARS-CoV; Bt: Bat SARS-CoV.

a 12-nt insertion (residues 1143 to 1146 of $1 a$ ) and a 3-nt deletion (residue 1155 of $1 a$ ). Other JPDB144 ORFs were the same as HKU4-4 in length, sharing aa identities of between $88.8 \%$ ( $3 c$ gene) and $98.8 \%$ ( $E$ gene); however, an aa sequence comparison of JPDB144 ORFs to those of HKU5 and MERS-CoV strains in the Betacoronavirus lineage 3 showed rather low similarities (Supplementary Table S4).

\section{DISCUSSION}

As shown in Figure 1, diverse $\alpha \mathrm{CoVs}$ and $\beta \mathrm{CoVs}$ have been identified in the present study from different bats sampled at 25 locations in 4 provinces and the Tibet Autonomous Region, demonstrating the wide distribution of CoVs among a range of bat species. Of $8 \alpha \mathrm{CoVs}$ identified, YDB5C is the first bat-borne $\mathrm{CoV}$ identified in the Tibet and Himalayan area, detected in 1 of 15 Hipposideros cineraceus bats collected in Yadong county of Tibet, located at the southern edge of the Himalayas bordering on Bhutan and India. Another newly identified CoV, MLHJC4, was detected in Rhinolophus sinicus in Yunnan province, which phylogenetically clustered closely with YDB5C, both showing 94\% nt identity to HKU2/GD/430/2006 identified in Guangdong (Lau et al, 2007), indicating that this type of $\alpha \mathrm{CoV}$ has a wide range of bat reservoirs and geo-distribution in south-west China and perhaps neighboring regions. In addition, six other $\alpha \mathrm{CoV}$ sequences JTAC2, MLHJC2, MLHJC6, MLHJC8, MLHJC22 and MLHJC34, found in this study clustered as two novel CoV groups. Although not novel, the $\beta \mathrm{CoVs}$ identified here showed abundance in genetic and geographical diversities. It is interesting to note that SARSr- and MERS-like CoVs were identified, particularly JTMC15 isolated in Jilin province - the first SAR$\mathrm{Sr}-\mathrm{Bat} \mathrm{CoV}$ to be discovered in Northeast China.

In consideration of bat species, sampling locations and CoVs diversities, four pathogen/host/environment situations can be proposed. First, a single bat species at one location (even a single cave) harboring different $\mathrm{CoV}$ species (e.g., Rhinolophus sinicus collected at the same site in Menglian county, Yunnan province, harboring three $\mathrm{CoV}$ species: HKU2-like, SARSr- and new $\alpha \mathrm{CoVs}$ ). Second, a single bat species roosting at different locations harboring the same CoVs (e.g., Rousettus leschenaulti collected in Mengla county (south Yunnan) and Wand- 
Table 2. Comparison of ORF amino acid identities of JTMC15 and other SARS- and SARSr- CoVs".

\begin{tabular}{|c|c|c|c|c|c|c|c|}
\hline \multirow[b]{2}{*}{ ORF } & \multirow{2}{*}{$\frac{\text { JTMC15 }}{\text { Length }}$} & \multicolumn{2}{|c|}{ Rf1 } & \multicolumn{2}{|c|}{ Rs672 } & \multicolumn{2}{|c|}{ BJ01 } \\
\hline & & Length & $\%$ identity & Length & $\%$ identity & Length & $\%$ identity \\
\hline $1 a$ & 4185 & 4378 & 98.0 & 4190 & 93.8 & 4383 & 93.5 \\
\hline $1 b$ & 2704 & 2704 & 98.1 & 2704 & 98.1 & 2704 & 98.0 \\
\hline$S$ & 1236 & 1241 & 86.1 & 1255 & 81.9 & 1241 & 76.7 \\
\hline $3 a$ & 274 & 274 & 98.2 & 274 & 92.0 & 274 & 86.2 \\
\hline $3 b$ & 114 & 114 & 97.4 & 114 & 91.3 & 114 & 90.4 \\
\hline$E$ & 76 & 76 & 94.8 & 76 & 96.1 & 76 & 96.1 \\
\hline M & 221 & 221 & 99.1 & 221 & 98.2 & 221 & 97.7 \\
\hline 6 & 63 & 63 & 96.9 & 63 & 92.2 & 63 & 89.1 \\
\hline $7 a$ & 122 & 122 & 98.4 & 122 & 93.5 & 122 & 91.9 \\
\hline $7 b$ & 52 & 44 & 83.0 & 44 & 84.9 & 44 & 79.2 \\
\hline $8(8 a)^{£}$ & - & 122 & - & 121 & - & 39 & - \\
\hline$-(8 b)$ & - & - & - & - & - & 84 & - \\
\hline$N$ & 420 & 421 & 98.1 & 422 & 96.7 & 422 & 96.2 \\
\hline $9 a$ & 97 & 97 & 94.9 & 98 & 79.6 & 98 & 79.6 \\
\hline $9 b$ & 70 & 70 & 94.4 & 70 & 83.1 & 70 & 84.5 \\
\hline
\end{tabular}

Note: "Abbreviation and accession numbers: Rf1, DQ412042; Rs672, FJ588686; BJ01, AY278488. ${ }^{\text {E}}$ Gene 8 in SARSr-CoVs is described as $8 a$ and $8 b$ in SARS-CoVs.

ing county (west Yunnan) harboring the same $\beta \mathrm{CoVs}$ ). Third, multiple bat species sampled at the same site harboring the same CoVs (e.g., Rousettus leschenaulti and Megaerops kusnotei sampled at the same location in Wanding county harboring the same $\beta \mathrm{CoVs}$ ). Different bat species collected at different locations may even harbor the same CoVs: e.g., a Hipposideros cineraceus in Yadong, Tibet and a Rhinolophus sinicus in Menglian, Yunnan harbored HKU2-like viruses, and another Rhinolophus sinicus in Menglian and a Rhinolophus ferrumequinum in Tonghua county, Jilin province, harbored SARSr CoVs. Altogether, the data provided further evidence for the wide distribution of CoVs among bat populations in China, and for the suggestion that different $\mathrm{CoVs}$ employ different bat species as reservoirs.

The present study has identified genetically diverse bat-borne $\mathrm{CoVs}$, which were detected from intestinal tissue specimens of different bat speices of wide geographic distribution. But we failed to detect any $\mathrm{CoV}$ sequence from the respiratory specimens that probably due to the low virus load in the lung or specific intestinetropism of $\mathrm{CoV}$ in bats. Bats are considered the gene source of Alphacoronavirus and Betacoronavirus (Woo et al, 2012), especially of pathogenic CoVs that cause public threats. In last decade, increasing number of $\mathrm{CoVs}$ have been identified in bats, in which the viral genes were presumably originated and evolved with high mutation and recombination rates (Woo et al, 2007). It is ap- parent that large numbers of circulating CoVs remain unidentified, and are evolving worldwide within the bat population. Investigations in unexplored regions are therefore urgently needed to gain further insights into $\mathrm{CoV}$ diversity and evolutionary dynamics.

\section{ACKNOWLEDGMENTS}

This work was supported by the Science and Technology Basic Work Program from the Ministry of Science and Technology of China (2013FY113600), NSFC-Yunnan Province Joint Fund (U1036601) and Military Medical Health (13CXZ024).

\section{COMPLIANCE WITH ETHICS GUIDELINES}

The authors declared that they have no conflict of interest. The whole study was approved by the Administrative Committee on Animal Welfare of the Institute of Military Veterinary, Academy of Military Medical Sciences, China (Laboratory Animal Care and Use Committee Authorization, permit number JSY-DW-2010-02). All institutional and national guidelines for the care and use of laboratory animals were followed.

\section{AUTHOR CONTRIBUTIONS}

CT conceived the study and LX carried it out with BH's 
guidance. FZ, WY, TJ, GL, TH, GC, YF, YZ, QF, JF and $\mathrm{HZ}$ were responsible for field investigation and bat sampling. TJ and GL identified bat species morphologically. XL took part in samples screening and CoVs detection. LX wrote the paper, CT and BH then revised it. All authors read and approved the final manuscript.

Supplementary figures/tables are available on the website of Virologica Sinica: www.virosin.org; link.springer. com/journal/12250.

\section{REFERENCES}

Baez-Santos YM, John SES, Mesecar AD. 2015. The SARScoronavirus papain-like protease: Structure, function and inhibition by designed antiviral compounds. Anti Res, 115: 21-38.

Chu DKW, Peiris JSM, Chen H, Guan Y and Poon LLM. 2008. Genomic characterizations of bat coronaviruses $(1 \mathrm{~A}, 1 \mathrm{~B}$ and HKU8) and evidence for co-infections in Miniopterus bats. J Gen Virol, 89: 1282-1287.

Falcon A, Vazquez-Moron S, Casas I, Aznar C, Ruiz G, Pozo F, Perez-Brena P, Juste J, Ibanez C, Garin I, Aihartza J, Echevarria JE. 2011. Detection of alpha and betacoronaviruses in multiple Iberian bat species. Arch Virol, 156: 1883-1890.

Gao F, Ou HY, Chen LL, Zheng WX, Zhang CT. 2003. Prediction of proteinase cleavage sites in polyproteins of coronaviruses and its applications in analyzing SARS-CoV genomes. FEBS Letters, 553: 451-456.

Ge XY, Li JL, Yang XL, Chmura AA, Zhu GJ, Epstein JH, Mazet JK, Hu B, Zhang W, Peng C, Zhang YJ, Luo CM, Tan B, Wang N, Zhu Y, Crameri G, Zhang SY, Wang LF, Daszak P, Shi ZL. 2013. Isolation and characterization of a bat SARS-like coronavirus that uses the ACE2 receptor. Nature, 503: 535-538.

He B, Zhang YZ, Xu L, Yang WH, Yang FL, Feng Y, Xia LL, Zhou JH, Zhen WB, Feng Y, Guo HC, Zhang HL, Tu CC. 2014. Identification of diverse alphacoronaviruses and genomic characterization of a novel severe acute respiratory syndrome-like coronavirus from bats in China. J Virol, 88: 7070-7082.

Kim Y-J, Cho Y-J, Kim D-W, Yang J-S, Kim H, Park SH, Han YW, Yun M-R, Lee HS, Kim A-R, Heo DR, Kim JA, Kim SJ, Jung H-D, Kim N, Yoon S-H, Nam J-G, Kang HJ, Cheong HM, Lee J-S, Chun J, Kim SS. 2015. Complete genome sequence of Middle East respiratory syndrome coronavirus KOR/KNIH/002 05_2015, isolated in South Korea. Genome Announc, 3: e00787-15.

Lai MMC, Perlman S, Anderson LJ. 2007. Coronaviridae. In: Fields Virology, Knipe DM and Howley PM (eds). Philadelphia: Lippincott Williams \& Wilkins, pp. 1305-1335.

Lau SKP, Poon RWS, Wong BHL, Wang M, Huang Y, Xu HF, Guo RT, Li KSM, Gao K, Chan KH, Zheng BJ, Woo PCY, Yuen KY. 2010. Coexistence of different genotypes in the same bat and serological characterization of Rousettus bat coronavirus HKU9 belonging to a novel Betacoronavirus subgroup. J Virol, 84:11385-11394.

Lau SKP, Woo PCY, Li KSM, Huang Y, Wang M, Lam CSF, Xu HF, Guo RT, Chan KH, Zheng BJ, Yuen KY. 2007. Complete genome sequence of bat coronavirus HKU2 from Chinese horseshoe bats revealed a much smaller spike gene with a different evolutionary lineage from the rest of the genome. Virology, 367: 428-439.

Li WD, Shi ZL, Yu M, Ren WZ, Smith C, Epstein JH,Wang HZ,
Crameri G, Hu ZH, Zhang HJ, Zhang JH, McEachern J, Field H, Dzszak P, Eaton BT, Zhang SY, Wang LF. 2005. Bats are natural reservoirs of SARS-like coronaviruses. Science, 310: 676-679.

Lu G, Wang Q, Gao GF. 2015. Bat-to-human: spike features determining 'host jump' of coronaviruses SARS-CoV, MERS$\mathrm{CoV}$, and beyond. Trends Microbiol, 23: 468-478.

Lu R, Wang Y, Wang W, Nie K, Zhao Y, Su J, Deng Y, Zhou W, Li Y, Wang H, Wang W, Ke C, Ma X, Wu G, Tan W. 2015. Complete genome sequence of Middle East respiratory syndrome coronavirus (MERS-CoV) from the first imported MERS-CoV case in China. Genome Announc, 3: e00818-15.

Menachery VD, Yount Jr BL, Debbink K, Agnihothram S, Gralinski LE, Plante JA, Graham RL, Scobey T, Ge XY, Donaldson EF, Randell SH, Lanzavecchia A, Marasco WA, Shi ZL, Baric RS. 2015. A SARS-like cluster of circulating bat coronaviruses shows potential for human emergence. Nat Med, 21: 1508-1513.

Moratelli R, Calisher CH. 2015. Bats and zoonotic viruses: can we confidently link bats with emerging deadly viruses? Mem Inst Oswaldo Cruz, Rio de Janeiro, 110: 1-22.

Neuman BW, Joseph JS, Saikatendu KS, Serrano P, Chatterjee A, Johnson MA, Liao L, Klaus JP, Yates III JR, Wuthrich K, Stevens RC, Buchmeier MJ, Kuhn P. 2008. Proteomics analysis unravels the functional repertoire of coronavirus nonstructural protein 3. J Virol, 82: 5279-5294.

Ren WZ, Qu XX, Li WD, Han ZG, Yu M, Zhou P, Zhang SY, Wang LF, Deng HK, Shi ZL. 2008. Difference in receptor usage between severe acute respiratory syndrome (SARS) coronavirus and SARS-like coronavirus of bat origin. J Virol, 82: 18991907.

Serrano P, Johnson MA, Chatterjee A, Neuman BW, Joseph JS, Buchmeier MJ, Kuhn P, Wuthrich K. 2009. Nuclear magnetic resonance structure of the nucleic acid-binding domain of severe acute respiratory syndrome coronavirus nonstructural protein 3. J Virol, 83: 12998-13008.

Sun M, Ma JL, Wang YN, Wang M, Song WC, Zhang W, Lu CP, Yao HC. 2015. Genomic and epidemiological characteristics provide new insights into the phylogeographical and spatiotemporal spread of porcine epidemic diarrhea virus in Asia. J Clin Microbiol, 53: 1484-1492.

Suzuki T, MurakamiS, Takahashi O, Kodera A, Masuda T, Itoh S, Miyazaki A, Ohashi S, Tsutsui T. 2015. Molecular characterization of pig epidemic diarrhoea viruses isolated in Japan from 2013 to 2014. Infect Genet Evol, 36: 363-368.

Tang XC, Zhang JX, Zhang SY, Wang P, Fan XH, Li IF, Li G, Dong BQ, Liu W, Cheung CL, Xu KM, Song WJ, Vijaykrishna D, Poon LLM, Peiris JSM, Smith GJD, Chen H and Guan Y. 2006. Prevalence and genetic diversity of coronaviruses in bats from China. J Virol, 80: 7481-7490.

Vlasova AN, MarthalerD, Wang Q, Culhane MR, Rossow KD, Rovira A, Collins J, Saif LJ. 2014. Distinct Characteristics and Complex Evolution of PEDV Strains, North America, May 2013-February 2014. Emerging Infect Dis, 20: 1620-1628.

Wacharapluesadee S, Duengkae P, Rodpan A, Kaewpom T, Maneeorn P, Kanchanasaka B, Yingsakmongkon S, Sittidetboripat N, Chareesaen C, Khlangsap N, Pidthong A, Leadprathom K, Ghai S, Epstein JH, Daszak P, Olival KJ, Blair PJ, Callahan MV, Hemachudha T. 2015. Diversity of coronavirus in bats from Eastern Thailand. Virol J, 12: 57-63.

Wang H, Liang B, Feng J, Sheng LX, Zhang SY. 2003. Molecular phylogenetic of hipposiderids (Chiroptera: Hipposideridae) and rhinolophids (Chiroptera: Rhinolophidae) in China based on mitochondrial cytochrome $b$ sequences. Folia Zool, 2: 259-268.

Woo PCY, Lau SKP, Lam CSF, Lau CCY, Tsang AKL, Lau JHN, Bai R, Teng JLL, Tsang CCC, Wang M, Zheng BJ, Chan KH, 
YuenKY. 2012. Discovery of seven novel Mammalian and avian coronaviruses in the genus Deltacoronavirus supports bat coronaviruses as the gene source of Alphacoronavirus and Betacoronavirus and avian coronaviruses as the gene source of Gammacoronavirus and Deltacoronavirus. J Virol, 86: 39954008.

Woo PCY, Wang M, Lau SKP, Xu HF, Poon RWS, Guo RT, Wong BHL, Gao K, Tsoi HW, Huang Y, Li KSM, Lam CSF, Chan K, Zheng BJ, Yuen K. 2007. Comparative analysis of twelve genomes of three novel group $2 \mathrm{c}$ and group $2 \mathrm{~d}$ coronaviruses reveals unique group and subgroup features. J Virol, 81: $1574-1585$

Yang L, Wu Z, Ren X, Yang F, He G, Zhang J, Dong J, Sun L, Zhu Y, Du J, Zhang S, Jin Q. 2011. Novel SARS-like betacoronaviruses in bats, China. 2013. Emerging Infect Dis, 19: 989-991. Yuan JF, Hon CC, LiY, Wang DM, Xu GL, Zhang HJ, Zhou P, Poon LLM, Lam TTY, Leung FCC, Shi ZL. 2010. Intraspecies diversity of SARS-like coronaviruses in Rhinolophus sinicus and its implications for the origin of SARS coronaviruses in humans. J Gen Virol, 91: 1058-1062. 